\title{
Development and release of a malacosporean (Myxozoa) from Plumatella repens (Bryozoa: Phylactolaemata)
}

\author{
David John Morris, Donald Charles Morris and Alexandra Adams
}

Institute of Aquaculture, University of Stirling, Stirling, Scotland, FK9 4LA, UK

Key words: Myxozoa, Tetracapsula, Bryozoa, culture, Buddenbrockia

\begin{abstract}
During an experiment to transmit Tetracapsula bryosalmonae Canning, Curry, Feist, Longshaw et Okamura, 1999 to a laboratory-cultured bryozoan, Plumatella repens L. a previously undescribed malacosporean species was noted. This parasite produced sacs of spores in the host that reached $1.2 \mathrm{~mm}$ in length. The spores released from the sacs appeared similar in size to the two species of Tetracapsula previously described although slight differences in form were noted. Release of spores from the bryozoans was observed associated with the lophophore of the host. The use of experimental bryozoan cultures for the examination of malacosporeans is described and discussed.
\end{abstract}

The phylum Myxozoa Grassé comprises more than 1,200 species. All of these species are endoparasitic and produce multi-cellular spores that contain nematocystlike polar capsules. Until recently, the phylum was composed of the classes Myxosporea Bütschli, and Actinosporea Noble. The taxonomy of both groups relies primarily on spore morphology (Lom and Arthur 1989, Lom et al. 1997). With the discovery that the life cycles of several myxosporean species produce actinosporean stages, Kent et al. (1994) proposed suppressing classification of the class Actinosporea in favour of the Myxosporea. However, there is concern over this proposed change, as uncertainty exists to whether all Actinosporea species will produce corresponding myxosporean stages in their life cycles (Lester et al. 1998).

In 1996, Canning et al. described an unusual species of myxozoan, Tetracapsula bryozoides in the bryozoan Cristatella mucedo Cuvier, which produced soft spore valves. Examination of further bryozoans identified another species, Tetracapsula bryosalmonae in both Fredericella sultana Blumenbach and a Plumatella sp. (Canning et al. 1999). Although light microscopy could not distinguish between the spores produced by these parasites, sequence comparison of respective $18 \mathrm{SS}$ rDNA gene segments and electron microscopy demonstrated that they were different species (Anderson et al. 1999).

Transmission experiments have recently established that $T$. bryosalmonae is the enigmatic PKX organism, which causes the economically important disease of salmonids, proliferative kidney disease, PKD (Feist et al. 2001). Phylogenetic studies on T. bryosalmonae and T. bryozoides demonstrated that both parasites formed a distinct clade within the Myxozoa (Kent et al. 1998, Anderson et al. 1999). Because of the unusual characteristics of the spores and the genetic distance from other myxozoan genera, a new class Malacosporea and order Malacovalvulida to include the genus Tetracapsula was formed (Canning et al. 2000).

The biology of malacosporeans within bryozoan hosts is largely unknown. For examination of bryozoan parasites it is desirable to develop continuous cultures of bryozoans in laboratory conditions. The majority of protocols for growing freshwater bryozoans rely on the use of water obtained from ponds or established aquaria to provide a range of protozoa and algae to act as feed (Hyman 1959, Wood 1989, Pennak 1989). Only one laboratory diet has been previously reported for the culture of a freshwater bryozoan. However, this diet utilised 12 species of protozoa, algae and rotifera and did not give details of the relative quantities of organisms used (Wayss 1968, Jebram 1980). Here we report on a simplified culture technique for the bryozoan Plumatella repens L. During an experimental attempt to transmit $T$. bryosalmonae from a salmonid to the cultured $P$. repens, we observed the development and release of a novel malacosporean species. This paper reports on these observations and the use of experimental bryozoan cultures to examine aspects of malacosporean biology.

\section{MATERIALS AND METHODS}

Collection and identification of bryozoan from the wild. A colony of the bryozoan Plumatella repens was obtained, attached to a branch collected from Airthrey Loch, Stirling, Scotland in August 2000. Tetracapsula bryosalmonae has never been recorded from the fish species inhabiting this Loch. The colony was $\sim 10 \mathrm{~cm}$ in diameter and when examined with a $\times 10$ hand lens appeared as a single entity with no evidence of fragmentation. It was removed along with adherent bark, from the branch, using a penknife. The attached colony was divided into 12 roughly equal pieces and any macro-invertebrates carefully removed under an inverted microscope, using forceps and pipette. The bark pieces were 
then glued onto four 9-cm plastic Petri dishes, three pieces a dish, using Loctite.

Culture of bryozoans. Two test-tube racks (Nalgene) were placed on their side into two 7-litre plastic aquaria. The Petri dishes containing the attached bryozoan colonies were inserted vertically into the interior spacing of the racks, two dishes per aquarium. The aquaria were then filled with artificial freshwater of intermediate hardness $\left(0.35 \mathrm{mM} \mathrm{CaSO}_{4}\left(2 \mathrm{H}_{2} \mathrm{O}\right)\right.$, $\left.0.5 \mathrm{mM} \mathrm{KCl}, 0.5 \mathrm{mM} \mathrm{MgSO}{ }_{4}\left(7 \mathrm{H}_{2} \mathrm{O}\right), 0.1 \mathrm{mM} \mathrm{NaHCO} 3\right)$, which were vigorously aerated and maintained at a constant $21^{\circ} \mathrm{C}$ using immersed, thermostatically controlled fish tank heaters. The water in the aquaria was replaced on a weekly basis. Bryozoan colonies were fed daily by introducing a mixture of full-grown culture suspensions into the tanks; Cryptomonas ovata Pringsheim $(300 \mathrm{ml})$; Synechococcus leopoliensis Komárek $(150 \mathrm{ml})$ and Pediastrum boryanum Myen $(50 \mathrm{ml})$. Cultures of Chilomonas paramecium Ehrenberg and Colpidium striatum Stokes (10 $\mathrm{ml}$ of each) were also introduced into the aquaria in the first week to seed them with protozoa. A commercial supplier (Sciento, Manchester, United Kingdom) was used to obtain the culture species. The diet was optimised for Plumatella spp. culture in a series of preliminary feeding experiments using a wide range of cultured algae, cyanobacteria and protozoan species (authors' unpublished data).

All of the colonies were examined daily under an inverted microscope. After two days, the bryozoans started to colonise the plastic of the Petri dishes. Culture continued for two weeks, during which time there was no evidence of Tetracapsula infection in any of the colonies. They were therefore considered malacosporean free and an attempt was made to transmit $T$. bryosalmonae to them.

After six weeks culture, at the termination of the experiment, released floatablasts (a specialised form of statoblast used as dispersal and overwintering stages for bryozoans) were collected from the aquaria surface water using a pipette. The intact colony form of the bryozoan on the branch, in conjunction with scanning electron microscopical examination of the collected floatablasts was used to identify the bryozoan using the published keys of Mundy and Thorpe (1980) and Ricciardi and Reiswig (1994). To determine the viability of floatablasts produced in the experimental culture conditions, 18 floatablasts were collected from the aquaria water surface and pipetted underneath inverted Petri dishes in an aquarium containing artificial freshwater. They were left undisturbed at $20^{\circ} \mathrm{C}$ for 4 days before being examined for hatching using an inverted microscope. The bryozoans arising from successfully hatched floatablasts were cultured as above, until floatablasts could again be harvested and used to seed fresh Petri dishes.

Experimental transmission of Tetracapsula bryosalmonae to cultured bryozoans. Two 2-year-old brown trout Salmo trutta L. were collected during August 2000 from a trout farm in Dumfriesshire, Scotland which is enzootic for PKD. The fish had been on the farm for 20 months exposing them to two PKD seasons. The kidneys of these fish were removed and laterally bisected. One half of the kidney was fixed in $10 \%$ buffered formalin for verification of $T$. bryo- salmonae infection, while the other half was forced through a disassociation sieve $(100 \mu \mathrm{m})$ into a Petri dish using the plunger from a $10-\mathrm{ml}$ syringe. After using $10 \mathrm{ml}$ of artificial freshwater to wash any remaining cells through the sieve, the resulting cell suspensions from the kidneys were added to one of the aquaria containing the bryozoan. Two brown trout kidneys obtained from a farm with no history of PKD were prepared as above and added to the other aquaria. The aquaria water in both tanks was changed the following day.

Tetracapsula bryosalmonae sporogonic stages and spores were verified in the fixed brown trout kidneys using immunohistochemistry with the monoclonal antibodies $\mathrm{C} 5$ and B4 and in situ hybridisation using the probes 6R, 1458 and 4R (Morris et al. 1997, 2000).

Examination of bryozoans for parasite infection. The bryozoans were examined for infection using an inverted microscope, daily for the first week following exposure, and then weekly. When a malacosporean infection was observed the colonies were again examined daily. The colonies of infected bryozoa were cultured for four weeks before they were terminated, while non-infected bryozoa were cultured for an additional three months.

Possible spore release from infected colonies through defecation was examined by collecting the faecal pellets discharged from infected colonies, squashing them on a slide under a coverslip, with a drop of water, and examining the contents under a microscope at $\times 400$ magnification.

Experimental exposure of rainbow trout to malacosporean spores. In an attempt to confirm successful transmission of T. bryosalmonae to the cultured bryozoans, rainbow trout Oncorhynchus mykiss Walbaum were exposed to the malacosporean spores obtained from infected colonies.

Using a scalpel blade, a portion of infected colony containing three mature spore sacs, as observed under a dissecting microscope, was cut from the Petri dish. It was placed in a drop of artificial freshwater on a glass slide and teased apart using forceps to release the spore sacs. After removing the bryozoan remains from the slide, the intact spore sacs were examined for spore release using phase contrast microscopy. A Zeiss KS300 image analyser was used to measure any spores released from the sacs.

Released spores were pipetted from the slide into a bijou containing $5 \mathrm{ml}$ of artificial freshwater and transferred to a static tank containing six rainbow trout (average weight $15 \mathrm{~g}$ ) and 31 of de-chlorinated tap water, aerated and maintained at $18^{\circ} \mathrm{C}$. The rainbow trout, obtained from a spring-fed trout farm with no history of PKD, remained in the tank for 1 hour. After exposure to the spores, the fish were transferred to a 150-litre flow-through tank supplied with de-chlorinated tap water at a constant $18^{\circ} \mathrm{C}$. A control group consisting of six rainbow trout obtained from the same farm were maintained in identical conditions but not exposed to spores. After seven weeks, the kidneys of both groups of fish were removed, fixed in formalin, processed into paraffin and sections cut onto glass slides. These were analysed using immunohistochemistry with the monoclonal antibodies $\mathrm{C} 5$ and $\mathrm{B} 4$ and in situ hybridisation using the probes $6 \mathrm{R}, 1458$ and $4 \mathrm{R}$ to determine the success of transmission (Morris et al. 1997, 2000). 


\section{RESULTS}

\section{Bryozoan culture}

The bryozoans were successfully grown onto the plastic of the Petri dishes. Invertebrates removed from the colonies before culture consisted of chironomids, cyclops, tardigrades, and oligochaetes of the family Naididae including Stylaria lacustris L. identified using the key of Brinkhurst (1963). Numerous ciliate protozoa were observed to grow in the tanks, presumably introduced adhered to the wood and colony. Rotifers of the genera Rotaria and Monostyla, Vorticella sp., gastrotrichs and small nematodes were also observed in the aquaria. The bryozoans were observed to ingest occasional Monostyla sp., gastrotrichs and nematodes but were never observed to ingest Vorticella sp. or Rotaria sp.

Of the 18 floatablasts examined for viability, 9 were successfully hatched and cultured onto Petri dishes. Colonies from these bryozoans were successfully cultured for a further four months before the cultures were terminated. During this time floatablasts were obtained from these colonies and successfully hatched and grown onto Petri dishes. Only Vorticella sp. appeared in the aquaria associated with these cultures. None of the bryozoans hatched from floatablasts contained malacosporean parasites.

Scanning electron microscopical examination of the floatablasts in conjunction with the original colony form of the bryozoan from the branch identified it as Plumatella repens The growth and morphological characteristics of the cultured $P$. repens colonies were comparable with previous studies on this species (Mukai et al. 1987). The older parts of the colony had a thickened, opaque cuticle, composed of inorganic particles. However, the cuticle remained clear on those parts of the colonies that had grown in the culture. The lack of this opaque cuticle allowed for the examination of the internal structures of the colony using an inverted microscope.

\section{Description of infected zooids}

Developing spore sacs were initially observed associated with two single zooids, which were adherent to the plastic of the Petri dish, two weeks after their exposure to the infected brown trout kidney. These zooids were the terminal zooids of bryozoan branches growing on the plastic that originated from colonies on different pieces of bark. The disintegration of a neighbouring zooid separated the common coelom (metacoel) of the main colonies from those of the infected terminal zooids. The colonies, from which these infected zooids separated, appeared parasite free for the duration of the experiment.

Three days after the first observations of bodies in the single zooids parasites were observed in a group of zooids. This group comprised of two branches consisting of four zooids each, which diverged from each other at the interface between the bark and the plastic. Neighbouring branches of zooids arising from this piece of wood remained uninfected suggesting that the infected branches were isolated from the rest of the colony arising from the bark. This presumably occurred on the surface of the bark, which did not allow for examination using a microscope. Therefore, exact numbers of infected zooids could not be determined. No other colony in either the experimental or the control aquaria were observed to be infected throughout the course of the experiment.

Four subsequent attempts at repeating the experiment to infect cultured $P$. repens colonies grown from floatablasts with $T$. bryosalmonae failed.

\section{Observations on malacosporean development}

The first parasites observed in the bryozoans were attached to the degenerated zooid of the two individually infected zooids. Initially they appeared as elongated sacs ( $\sim 300 \mu \mathrm{m}$ long), lined with cells (Fig. 1) with two sacs per zooid. These sacs continued to elongate and started to differentiate with cell masses developing, lining the inside of the sac. At this stage, free-floating cells were also observed in the lumen of the sac. The accumulation of cells in the lumen of the sac continued with the cells developing into spores (Fig. 2). As the sac filled with spores and pre-spore stages, the sac wall became reduced until it was $4 \mu \mathrm{m}$ in width and appeared to be composed of an outer and an inner membrane. The apex of the mature sac was thickened and composed of undifferentiated cells (Fig. 3). The sacs detached from the remains of the zooid where they floated in the metacoel. The maximum length of mature spore sacs, as designated by the large quantity of spores within them, varied between $900 \mu \mathrm{m}$ and $1.2 \mathrm{~mm}$.

As the infection progressed, more spore sacs developed inside the infected bryozoan. They then began to elongate, where they resembled the first stages observed in the bryozoans. These sacs floated freely in the metacoel of the bryozoans. Both the immature and mature sacs appeared to have a writhing, serpentine motion, reminiscent of nematodes. This was presumably due to cilia lining the metacoel's epithelium moving coelomic fluid around the sacs. Spores were observed to be free-floating in the lumen of the mature sacs, moving independently of the enclosing membranes. Often mature spore sacs could be observed, wrapped around the gut of the bryozoan, towards the base of the lophophore. Localised constrictions, towards the ends of the sacs, suggestive of budding, were noted on all stages of sac development. All stages of sac development were observed at the same time in the same colony. The number of spore sacs varied over the course of the infection and was related to the size of the colonies. The single infected zooids only contained two mature spore sacs at one time but could contain a further five immature sacs while the number of mature sacs in the group of zooids was estimated at greater than eight at one time (sacs in the portion of this colony on the bark could not be counted). 

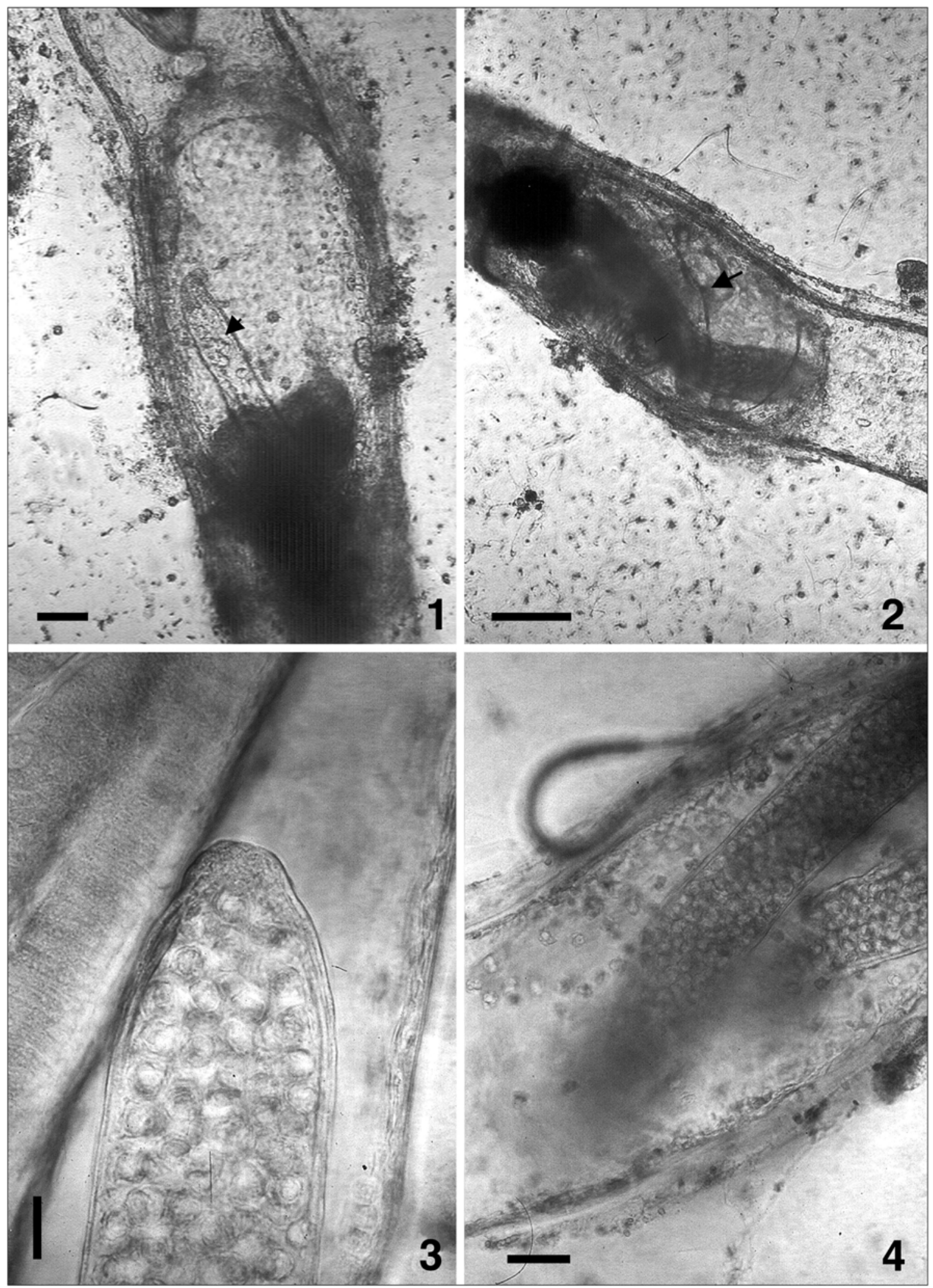

Figs. 1-4. Spore sac development of malacosporean observed in Plumatella repens. Fig. 1. Initial developmental parasite sac observed in bryozoan (arrowhead) attached to a degenerate zooid. Fig. 2. Mature spore sac in bryozoan connected to degenerate zooid (arrowhead indicates an immature sac is also present). Fig. 3. Apex of mature spore sac, filled with spores, showing that it is undifferentiated compared to the rest of the encapsulating spore sac membrane. Fig. 4. Rupturing of mature sacs, releasing spores into the metacoel of bryozoan. Scale bars: Fig. $1=75 \mu \mathrm{m}$; Fig. $2=150 \mu \mathrm{m}$; Fig. $3=25 \mu \mathrm{m}$; Fig. $4=60 \mu \mathrm{m}$. 

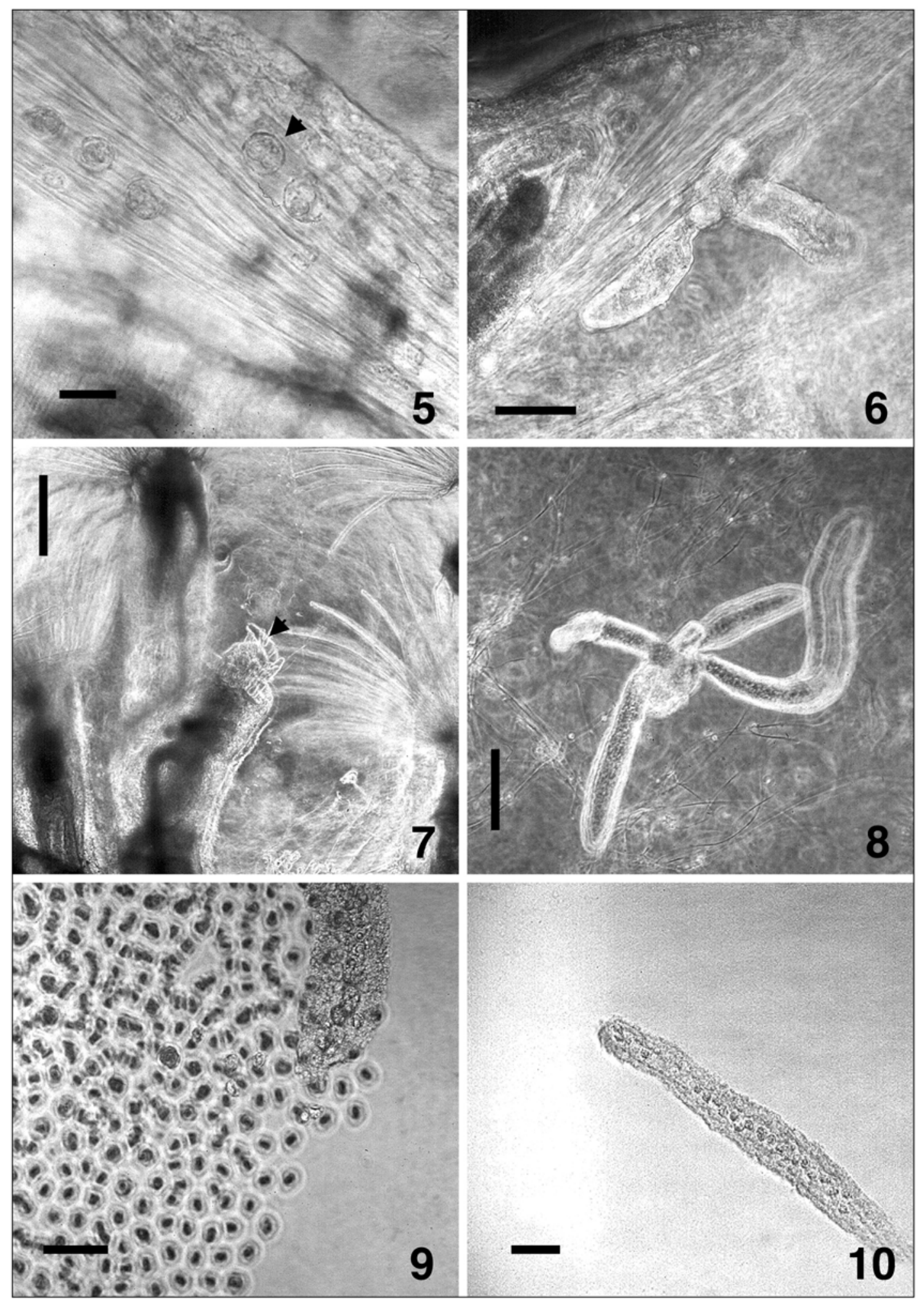

Figs. 5-10. Malacosporean spores and spore sac after the rupturing of a sac. Fig. 5. Released spores in metacoel of bryozoan. Arrowhead indicates some spores that have become temporarily ensnared on the retractor muscle of the zooid. Fig. 6. Misshapen spore sac in metacoel of bryozoan. Fig. 7. Ejection of spore sac from bryozoan. Tip of the spore sac is observable between the retracted tentacles of the zooid (arrowhead). Fig. 8. Ejected spore sac in Petri dish. Fig. 9. Release of spores from spore sac dissected from bryozoan. All of the spores exit the sac from one end. Fig. 10. Remains of spore sac after rupturing. Some spores can still be observed inside the sac. Scale bars: Fig. $5=25 \mu \mathrm{m}$; Figs. $6,8=50 \mu \mathrm{m}$; Fig. $7=350 \mu \mathrm{m}$; Figs. $9,10=75 \mu \mathrm{m}$. 


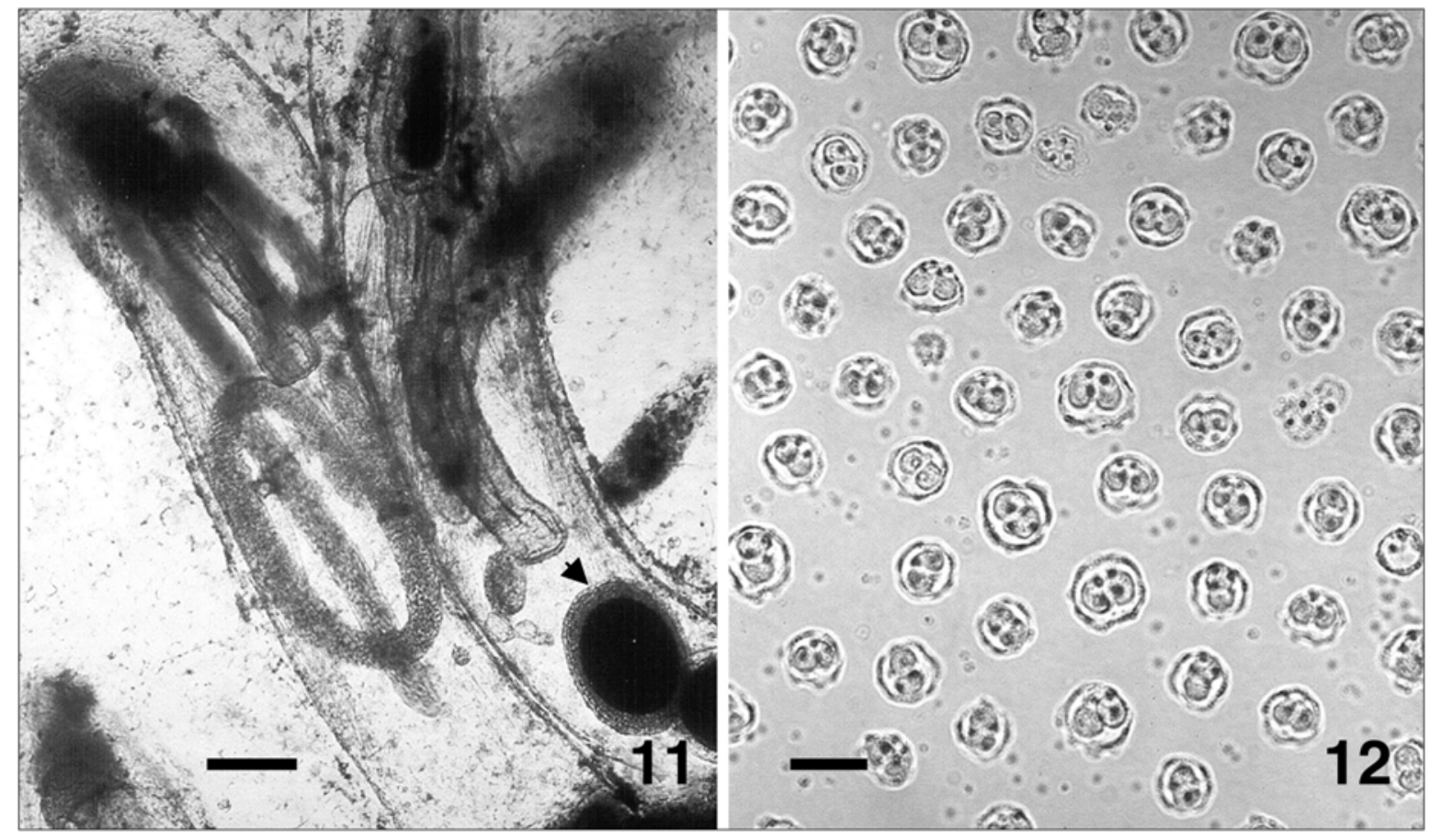

Figs. 11-12. Malacosporean spores and spore sacs. Fig. 11. Two neighbouring bryozoan colonies growing alongside of one another in culture. The colony on the left is infected with the malacosporean whilst the colony on the right is not infected. Note that statoblasts (arrowhead) only develop in the non-infected colony. Fig. 12. Fresh spores released from dissected spore sac. Scale bars: Fig. $11=200 \mu \mathrm{m}$; Fig. $12=20 \mu \mathrm{m}$.

\section{Release of spores from bryozoans}

When the spore sacs had fully developed, the delimiting membranes ruptured at one end, releasing the spores into the coelom of the bryozoan (Fig. 4). The first observed release of mature spores from sacs occurred 17 days after the colonies were exposed to $T$. bryosalmonae. These released spores were rapidly disseminated throughout the whole colony by the movement of the coelomic fluid (Fig. 5). In particular, they were observed to collect in the lumina of the lophophore arms, although they were never observed to pass into the tentacles themselves. In the arms the spores would rapidly spin on their axis, polar capsules facing the tentacles of the lophophore, presumably moving with the motion of the coelomic fluid. While spinning, the spores would appear coniform, reflecting the plasticity of the encapsulating cells.

When spores were to be released, the lophophore would retract. Around 20 spores would then be released from between the tentacles of the retracted lophophore. Exact numbers were difficult to determine as the currents generated by neighbouring lophophores rapidly dispersed them. The retracted lophophore would then extend and continue filtering water normally. Released spores were observed throughout the water of the Petri dish, although they often appeared to come to rest on the plastic, however even a slight water movement would re-suspend them again. Spores were never observed to be released from the bryozoans either through the body wall, during defecation or in any of the faecal pellets examined. Occasionally a misshapen spore sac would be extruded from the lophophore. When this occurred, the retracted lophophore would briefly convulse and a portion of the spore sac would appear out between the retracted tentacles (Figs. 6, 7). The sac would then be released, often in conjunction with free spores. These sacs always had the superficial appearance of immature sacs, as they never contained spores (Fig. 8). However, unlike immature spore sacs they appeared to be composed of several interlocking lobes. The ejected sacs also appeared to move in the Petri dish, slowly flexing, independent of local water currents.

When the three mature sacs were dissected from infected zooids, for transmission to rainbow trout, they ruptured (around $30 \mathrm{~s}$ after release from zooid) to discharge spores. The sacs ruptured at one end, releasing spores into the water of the slide (Fig. 9). This appeared to occur under pressure as the sac rapidly deflated while the spores were being released. A few spores were noted to persist in the sacs after they had deflated (Fig. 10).

\section{Effects of malacosporean on Plumatella repens colonies}

The parasite had limited deleterious effect on the three infected $P$. repens colonies observed. Growth of the infected colonies was comparable to neighbouring 


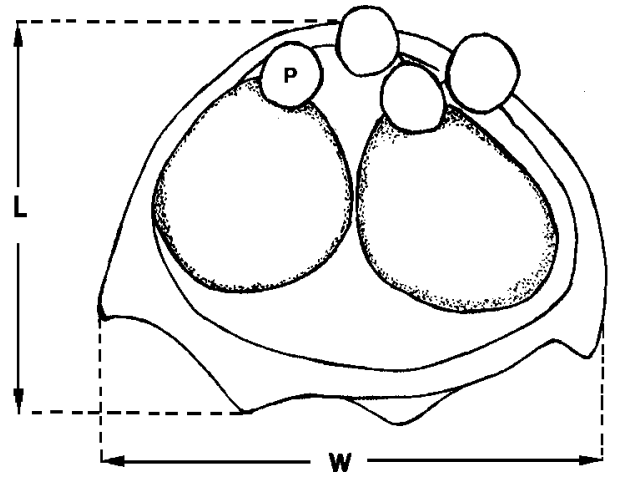

Fig. 13. Schematic drawing of spore of malacosporean indicating the ornamentation observed on the spore, two sporoplasms and the four spherical polar capsules $(\mathrm{P})$ each $1 \mu \mathrm{m}$ in diameter. $\mathrm{W}=19.0 \mu \mathrm{m} \mathrm{SD} \pm 1.0(\mathrm{n}=54), \mathrm{L}=16.4$ $\mu \mathrm{m} \mathrm{SD} \pm 0.6(\mathrm{n}=19)$.

non-infected colonies. However, although statoblast production was observed in all of the non-infected bryozoans it was never observed in the infected ones. Response times of lophophore retraction to physical stimulus appeared normal when compared to noninfected colonies. Although degenerate zooids were detected these were in the older parts of the colony and were comparable to normal senescence. After four weeks, branches of some infected and non-infected colonies were observed growing alongside each other. However, transmission was never noted to cross from the infected colony to any of the non-infected colonies either on the same Petri dish or in the same aquaria (Fig. 11).

\section{Description of mature spores}

The description of mature spores is based on those released from the dissected spore sacs. The mature spores consisted of four cytoplasmic valve cells enclosing two sporoplasms with four spherical polar capsules situated at one pole (Fig. 12). The polar capsules were of equal size (about $1 \mu \mathrm{m}$ in diameter), although the number of turns of the polar filaments could not be discerned. The valve cells formed observable sutures, when viewed under Nomarski interference microscopy, between the polar capsules, with one polar capsule to each valve cell. The sporoplasms were located immediately posterior to the polar capsules and measured $10 \mu \mathrm{m} \times 8 \mu \mathrm{m}$. Although most of the expelled spores appeared mature, with four discernible round polar capsules, a few spores still appeared to be developing and occasional spores appeared malformed possessing two or three polar capsules. As these spores were relatively unusual, the development of spores in the sacs appears to be almost synchronous. The spores resembled those described for the two currently identified species of Tetracapsula although instead of spherical they were slightly flattened, measuring about $19 \mu \mathrm{m}$ in diameter by $16 \mu \mathrm{m}$ in height. There was also evidence of ornamentation consisting of a slight drawing out of the bottom corners of the spore. A schematic diagram of a mature spore is presented in Fig. 13.

Transmission of malacosporean to rainbow trout

Tetracapsula bryosalmonae was not detected in any of the rainbow trout exposed to the spores.

\section{DISCUSSION}

Often, bryozoan colonies collected from the wild are encrusted with inorganic material making examination of their contents difficult (Pennak 1989). The relative transparency of the cultured bryozoan in this study allowed infected colonies to be easily identifiable and resulted in a number of important observations on parasite development to be made. A preliminary study using the culture method suggests that it is suitable for culturing a range of freshwater bryozoa including Fredericella sultana Blumenbach and Plumatella emarginata Allman (authors' unpublished data). Previous studies on Tetracapsula spp. have relied on examining bryozoans collected fresh from the wild for infection. Cementing collected bryozoans onto Petri dishes and culturing them using the simplified diet described in this paper, enables the parasitised colonies to be maintained for long periods of time in the laboratory allowing for a variety of studies to be conducted on them.

The size of the spore sacs observed, ornamentation of the spore and failure to transmit the malacosporean parasite to rainbow trout suggests that it is not Tetracapsula bryosalmonae. Discrimination between Tetracapsula species presently relies on ultrastructural and molecular data, specifically the sequence of the $18 \mathrm{SS}$ rDNA gene. These studies will need to be conducted on the malacosporean noted in this study before it can be precisely classified and its relationship with $T$. bryosalmonae be properly assessed. Although it is possible that the bryozoan was already parasitised when it was collected, the infection of the terminal zooids on branches that had developed, while in culture, suggests that transmission took place in the aquaria. If the observed parasite is not $T$. bryosalmonae, then this transmission may have occurred for a number of reasons; the presence of an invertebrate releasing infective parasites into the aquaria; the parasites freeliving on the bark; the trout used to infect the bryozoan had a concurrent, undiagnosed malacosporean infection or the Tetracapsula parasites associated with PKD can be ascribed to more than one species of malacosporean.

The life cycles of malacosporeans remain enigmatic. Although, only a limited number of infected bryozoan colonies were observed in this study, statoblast production was never noted suggesting that it is inhibited in Plumatella repens by the parasite. Statoblasts are considered to be both overwintering and dispersal stages of Plumatella sp. (Pennak 1989). As there was no evidence of released spores infecting other colonies in 
the aquaria, we suggest that an alternative host is required in the life cycle of this species of malacosporean. The inhibition of statoblasts may also have implications for the identification of infected bryozoa collected from the wild as they are the primary characteristic used for the differentiation of different Plumatella species (Mundy and Thorpe 1980).

The development of the malacosporean, in the individually infected zooids, suggests that the formation of the initial spore sacs involves the degeneration of a zooid. From the degenerated zooid the parasite is able to infect the metacoel of the bryozoan and develop. However, the degeneration of the zooid also isolated the infected zooids, thus limiting the spread of the parasite through the colony. This may present a mechanism by which a bryozoan colony can limit the extent of malacosporean infection. It is unclear whether all of the malacosporean sacs in the bryozoan were derived from the remains of the degenerated zooid or once they became detached they could proliferate independently. The budding of sacs suggests a mechanism by which they could replicate within the metacoel of the host. This budding has also been noted for the spore sacs of Tetracapsula bryozoides (Okamura 1996). The synchronous development of the spores within the sacs correlates to observations on the development of spores of T. bryosalmonae (Canning et al. 2000).

The route of exit of the parasites was associated with the lophophore and not with defecation. Due to compression of structures when the lophophore retracts it was impossible to observe the exact route of exit. However, the mesocoel, and tentacles of the lophophore are believed to be the chief excretory sites of freshwater bryozoa, removing cell debris from the metacoel (Hyman 1959). It is possible that these excretory structures are the method by which spores are released from the host. Although data is limited, this route of exit may also be used by other malacosporeans. For example in Cristatella mucedo colonies, infected with T. bryozoides, spore sacs were observed to collect in the mesocoel causing local deformation of the bryozoan tissues (Okamura 1996). Another method of release would be from the vestibular pore, which is used by bryozoa to release statoblasts from the metacoel into the environment. This pore has been reported as a method of release for the microsporidium parasite Nosema bryozoides Korotneff (Marcus 1941). For P. repens, these pores have been associated with the lophophore (Wayss 1969). The rupturing of mature sacs, releasing spores into the bryozoan coelom was often observed in this study. The rupturing of sacs was also reported for $T$. bryozoides, although the fate of the released spores was not observed (Okamura 1996). The ejection of individual spores, rather than sacs from the lophophore, appears to be the primary manner in which the parasite is released into the environment. The ejection of spore sacs has been noted for both T. bryosalmonae and $T$.

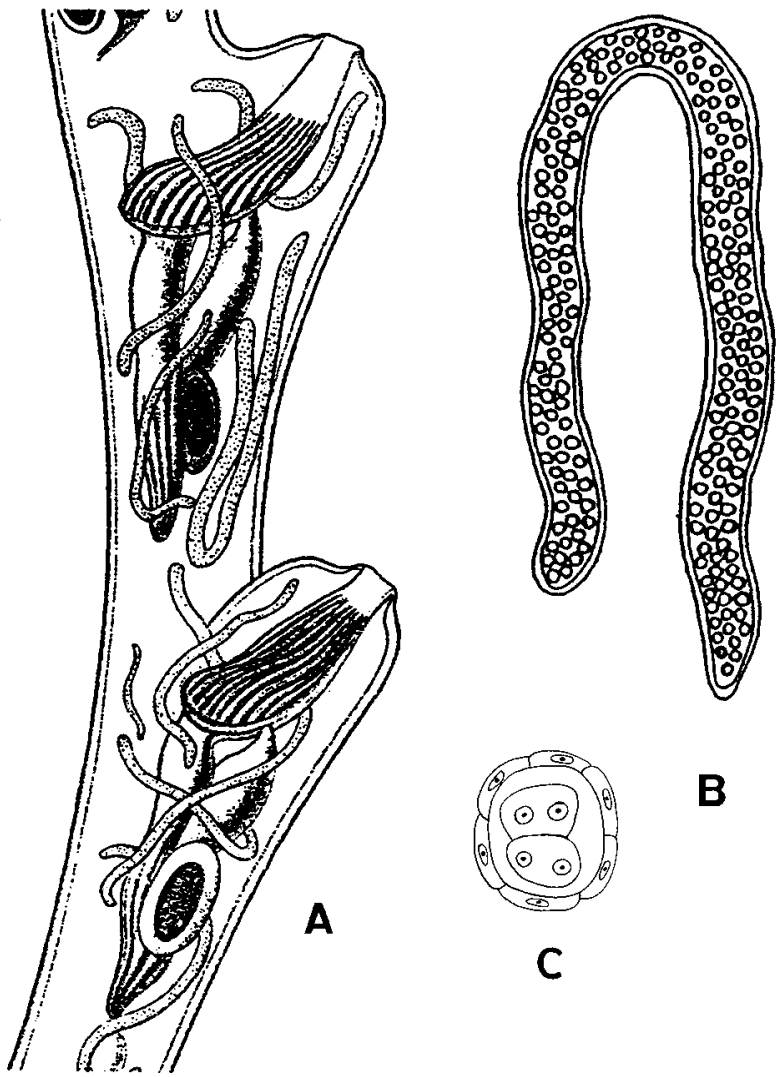

Fig. 14. Aspects of the development of Buddenbrockia plumatellae, demonstrating its affinities with the Malacosporea. The drawings indicate the vermiform nature of the parasite in the metacoel (A), the filling of the vermiform parasites' lumen with 'ovocytes' (B) and the morphology of the 'ovocytes' (C) (from Schröder 1910). Exact measurements of the drawings were not included in the original paper.

bryozoides, although it requires the mechanical compression of the colony and therefore is likely be an unusual event in the natural environment. These mechanically released sacs contained mature and maturing spores (Okamura 1996, Longshaw et al. 1999). For the malacosporean observed in this study, the spore sacs that were released naturally, never contained visible spores. The nature of the expelled spore sacs is uncertain, as they appear to be morphologically different from other developing sacs. However, they probably represent the deformed remains of mature sacs that have ruptured in the coelom of the bryozoan. The limited movement associated with the ejected sacs is likely to be due to osmotic changes, while the vigorous movement of spore sacs within bryozoan can be ascribed to the circulation of coelomic fluid by cilia lining the peritoneum (Okamura 1996).

Schröder $(1910,1912)$ described a vermiform parasite infecting Plumatella fungosa Pallas and P. repens that he named Buddenbrockia plumatellae. Marcus (1941) reviewed the taxonomic position of B. plumatel- 
lae but concluded that it could not be ascribed to any known group. Superficially, B. plumatellae resembled a degenerate nematode, which as it developed, filled with what were considered to be ovocytes containing polar bodies. The description of $B$. plumatellae closely resembles the malacosporean observed in this study with the described ovocytes correlating closely to mature malacosporean spores with polar capsules (Fig. 14). These features lead us to suggest that $B$. plumatellae is a member of the Malacosporea. The development of $B$. plumatellae appears to be different from the parasite recorded in this study as statoblast formation was observed in infected colonies, the sacs were $1.5 \mathrm{~mm}$ in length and the ovocytes (spores) described were spherical. As such, it probably represents a related species of malacosporean. Incidence of $B$. plumatellae has been reported from Belgium, Germany, Turkistan and Brazil in a range of bryozoan hosts, although accounts differ on the size of the sacs observed depending upon the host (reviewed by Marcus 1941). This diversity of sac size and hosts suggests that the reports describe several different parasite species that resemble $B$. plumatellae. In marine bryozoa, vermiform bodies thought to be parasites of an uncertain taxon have also been described (Hastings 1943). It is possible that these bodies are also related to the parasite observed in this study indicating that many more species of malacosporeans exist which infect bryozoa species.

Acknowledgements. The authors would like to thank Dr. James Bron, University of Stirling for assistance with image analysis and Dr. Eva Randall and Astrid Holzer, University of Stirling for their help in translating texts. This investigation was supported by a grant from MAFF CSG and a studentship from the Natural Environment Research Council UK.

\section{REFERENCES}

ANDERSON C.L., CANNING E.U., OKAMURA B. 1999: Molecular data implicate bryozoans as hosts for PKX (Phylum Myxozoa) and identify a clade of bryozoan parasites within the Myxozoa. Parasitology 199: 555-561.

BRINKHURST R.O. 1963: A Guide for the Identification of British Aquatic Oligochaeta. Freshwat. Biol. Assoc. Sci. Publ. 22, 1-52.

CANNING E.U., CURRY A., FEIST S.W., LONGSHAW M., OKAMURA B. 1999: Tetracapsula bryosalmonae n.sp. for PKX organism, the cause of PKD in salmonid fish. Bull. Eur. Assoc. Fish Pathol. 19: 203-206.

CANNING E.U., CURRY A., FEIST S.W., LONGSHAW M., OKAMURA B. 2000: A new class and order of myxozoans to accommodate parasites of bryozoans with ultrastructural observations on Tetracapsula bryosalmonae (PKX organism). J. Euk. Microbiol. 47: 456-468.

CANNING E.U., OKAMURA B., CURRY A. 1996: Development of a myxosporean parasite Tetracapsula bryozoides gen. n. et sp. n. in Cristatella mucedo (Bryozoa: Phylactolaemata). Folia Parasitol. 43: 249-261.

FEIST S.W., LONGSHAW M., CANNING E.U., OKAMURA B. 2001: Induction of proliferative kidney disease (PKD) in rainbow trout via the bryozoan Fredericella sultana, infected with Tetracapsula bryo-salmonae. Dis. Aquat. Org. 45: 61-68.

HASTINGS A. 1943: Polyzoa. Discovery Rep. 22: 303-505.

HYMAN L.H. 1959: The Invertebrates. Vol. 5. McGraw-Hill, New York, 783 pp.

JEBRAM D. 1980: Laboratory diets and qualitative nutritional requirements for bryozoans. Zool. Anz. 205: 333-344.

KENT M.L., KHATTRA J., HERVIO D.M.L., DEVLIN R.H. 1998: Ribosomal DNA sequence analysis of isolates of the PKX myxosporean and their relationship to members of the genus Sphaerospora. J. Aquat. Anim. Health 10: 1221.

KENT M.L., MARGOLIS L., CORLISS J.O. 1994: The demise of a class of protists: taxonomic and nomenclatural revisions proposed for the protist phylum Myxozoa Grassé, 1970. Can. J. Zool. 72: 932-937.
LESTER R.J.G., HALLETT S.L., EL-MATBOULI M., CANNING E.U. 1998: The case for naming actinosporeans using the Zoological Code. Parasitol. Today 14: 476-477.

LOM J., ARTHUR J.R. 1989: A guideline for the preparation of species descriptions in Myxosporea. J. Fish Dis. 12: 151-156.

LOM J., McGEORGE J., FEIST S.W., MORRIS D., ADAMS A. 1997: Guidelines for the uniform characteri-sation of the actinosporean stages of parasites of the phylum Myxozoa. Dis. Aquat. Org. 30: 1-9.

LONGSHAW M., FEIST S.W., CANNING E.U., OKAMURA B. 1999: First identification of PKX in bryozoans from the United Kingdom - molecular evidence. Bull. Eur. Assoc. Fish Pathol. 19: 146-148.

MARCUS E. 1941: Sôbre Bryozoa do Brasil. Zoologia, Univ. São Paulo, Brasil 10: 3-207.

MORRIS D.J., ADAMS A., RICHARDS R.H. 1997: Studies of the PKX parasite in rainbow trout via immunohistochemistry and immunogold electron microscopy. J. Aquat. Anim. Health 9: 265-273.

MORRIS D.J., ADAMS A., RICHARDS R.H. 2000: In situ hybridisation identifies the gill as a portal of entry for PKX (Phylum Myxozoa), the causative agent of proliferative kidney disease in salmonids. Parasitol. Res. 86: 950-956.

MUKAI H., FUKUSHIMA M., JINBO Y. 1987: Characterisation of the form and growth pattern of colonies in several freshwater bryozoans. J. Morphol. 192: 161-179.

MUNDY S.P., THORPE J.P. 1980: Biochemical genetics and taxonomy in Plumatella coralloides and P. fungosa and a key to the British and European Plumatellidae (Bryozoa: Phylactolaemata). Freshwater Biol. 10: 519-526.

OKAMURA B. 1996: Occurrence, prevalence and the effects of the myxozoan Tetracapsula bryozoides parasitic in the freshwater bryozoan Cristatella mucedo (Bryozoa: Phylactolaemata). Folia Parasitol. 43: 262-266. 
PENNAK R.W. 1989: Fresh-water Invertebrates of the United States: Protozoa to Mollusca. Third Edition. John-Wiley, New York, $628 \mathrm{pp}$.

RICCIARDI A., REISWIG H.M. 1994: Taxonomy, distribution and ecology of the freshwater bryozoans (Ectoprocta) of eastern Canada. Can. J. Zool. 72: 339-359.

SCHRÖDER O. 1910: Buddenbrockia plumatellae eine neue Mesozoenart aus Plumatella repens L. and Pl. fungosa Pall. Ztschr. Wissensch. Zool. 96: 525-535.

Received 13 March 2001
SCHRÖDER O. 1912: Zur Kenntnis der Buddenbrockia plumatellae O. Schröder. Ztschr. Wissensch. Zool. 102: 79-91.

WAYSS K. 1968: Quantitative Untersuchungen über Wachstum und Regeneration bei Plumatella repens (L.). Zool. Jahrb. Anat. 85: 1-50.

WOOD T.S. 1989: Ectoproct bryozoans of Ohio. Ohio Biol. Surv. Bull. (n.s.) 8: 1-70.

Accepted 12 July 2001 